\title{
Improving the heat transfer efficiency of a direct-flow recycling boiler using organic fluid
}

\author{
M.A. Peretyatko ${ }^{1}$, P.V. Yakovlev ${ }^{1}$, S.A. Peretyatko ${ }^{2}$ \\ ${ }^{1}$ Department of Heat Power Engineering,Faculty of Power Engineering, SaintPetersburg Mining \\ University, St. Petersburg, Russia \\ ${ }^{2}$ Department of Metrology Instrumentation and Quality Management, Faculty of Mechanical \\ Engineering, SaintPetersburg Mining University, Russia, St. Petersburg, Russia
}

\begin{abstract}
This paper considers the problem of studying the heat transfer exchange during boiling in a direct-flow recycling boiler using an organic coolant. The study was conducted using numerical modelling in the ANSYS software package. Asaresultofthestudyavisual picture eofvaporphasedistributionwasobtained. This picture shows that the studied heat-exchange surface can be conditionally divided into two areas: the area of intense vaporization and the area in which the degree of dry vapor varies insignificantly. Analysis of changes in the heat transfer coefficient along the length of the heat-exchange surface led to the conclusion that heat transfer in the second area is inefficient. Based on the results of the study, it was concluded that intensification of heat transfer is necessary, for which it is proposed to install a separator at the boundary between the selected areas. The subject of the study is the dependence of the variationin the heat transfer coefficient along the length of the pipe and the determination of the boundary between the selected areas at various values of the defining parameters. Numerical simulation for therange of variationofthe defining parameters corresponding to the actual temperature regimeof power steam boilers and the conditions for the implementation of heat recovery in organic Rankine cycle unitswas performed.
\end{abstract}

\section{Introduction}

The policy of introducing energy-saving technologies, implemented in recent years, determines the need tomaximize the use of waste heat ofvarious enterprises, power plants, and boiler houses [1]. The temperature potential of heat discharged into the environment is limited by temperatures of $80 \div 130^{\circ} \mathrm{C}$. Such sources are very common in the oil, metallurgical chemical, and other industries [2]. The use of this heat for heating is limited by current regulations requiring the maintenance of water temperature in heating systems above the temperature of low-temperature heat sources.

Available low-temperature heat can be used to generate electrical poweratsmall power plants based on the principle of the organic Rankine cycle (ORC).

Currently, thermal power plants operating on the Rankine cycle are quite common. Around $85 \%$ of the world's electricity is generated by the Rankine cycle [3]. 
The organic Rankine cycle works on the same principle as the classic Rankine cycle with water as thefluid. The main difference between the organic fluid and water is thelow boiling point, which allows the production of steam at low temperatures of heat sources.

There are several main types of ORC units. A schematic diagram of the ORC unit is presented in Figure 1.
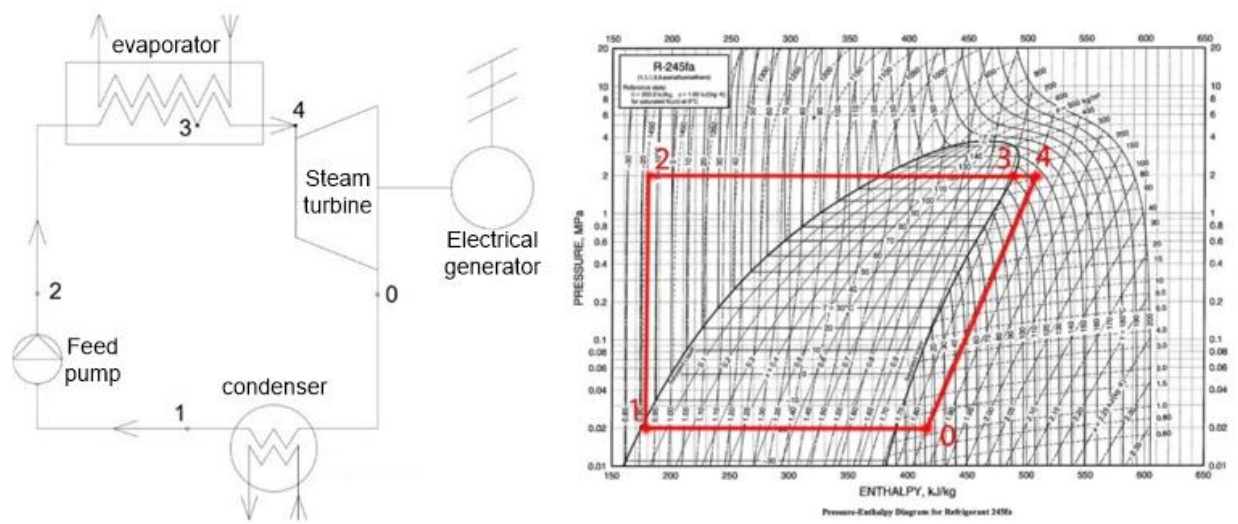

Fig.1. Schematic diagram of the ORC unit.

As it can be seen from Figure 1, the ORC unit includes:

1 - condenser, in which heat is removed from the vapor-liquid mixture at the outlet of the turbine; in the process of heat removal, the vapor-liquid mixture condenses

2 - feed pump, in which the pressure of organic fluidcondensateafter the condenser is increased to the required parameters

3 - evaporator, in which heat is supplied from a low-temperatureheat source to an organic coolant, in which organic fluid evaporates and overheating of steam occurs

4 - steam turbine, in which the thermal energy of the stream is first converted to power energy, and then to the mechanical energy of rotation of the turbine rotor with an electric generator, in which the mechanical energy of the turbine rotor is converted to electrical energy.

Let's consider the evaporator in more detail. The evaporator is a direct-flow boiler with minimal aerodynamic drag, in which a liquid fluid is fed to the pipe inlet and saturated steam comesout. The proliferation of CRO installations is held back forseveral reasons.

One of the main reasons is the high steam vacuum in the last sections of the evaporator [4]. Feeding steam with an insufficient degree of dryness leads to wet steam enteringthe turbogenerator with droplets of liquid. This leads to the destruction of the turbine blades. An increase in the heat transfer surface to ensure a margin of dryness value of steam leads to an increase in the cost and complexity of the design of the direct-flow boiler $[5,6]$.

Thus, to solve this problem, it is necessary to study the heat transfer in the evaporator. Itsstudy is complicated by the presence of a phase transition, i.e., evaporation of the fluid in the pipes of the heat exchanger [7,8]. The I study aims to determine the nature of the change in the heat transfer coefficient along the length of the pipe during the boiling process and to define the boiling pattern.

\section{Model description}

The study of heat transfer in the evaporator was carried out using numerical simulation in the ANSYS software package. 
Geometrically, the studied model is an evaporator pipe of the ORC unit with an internal diameter of $32 \mathrm{~mm}$. The length of the straight pipe section and the bending radius of the pipe are equal to $0.5 \mathrm{~m}$ and $0.052 \mathrm{~m}$, respectively. The number of pipe turns is 7 .

Steel was used as the pipe material. N-pentane was chosen as a fluid. The saturation temperature of the fluid is $309^{\circ} \mathrm{K}$. Newton's boundary conditions were set as boundary conditions.

Thermal energy is transferred to the fluid from the pipe walls with a temperatureof $450^{\circ} \mathrm{K}$ from the outside. The fluid pressure was equal to atmospheric. The time step was taken $0.01 \mathrm{~s}$. The number of iterations was 500 . Thus, $5 \mathrm{~s}$ of theboiling process of the fluid from the liquid state to the steady state was simulated.

The calculation of the next step parameters was based on the calculated parameters ofthe previous step. The calculation was carried out in Ansys software version 19R3 using the Fluent module.

\section{Simulation results}

One of the simulation results is the boiling picture of the fluid in the heat exchanger tube. This picture was obtained for each iteration. Boiling patterns for iteration number 100 and 300 are presented in Figure2. The resulting boiling pattern for the final iteration №500 is presented in Figure 3.
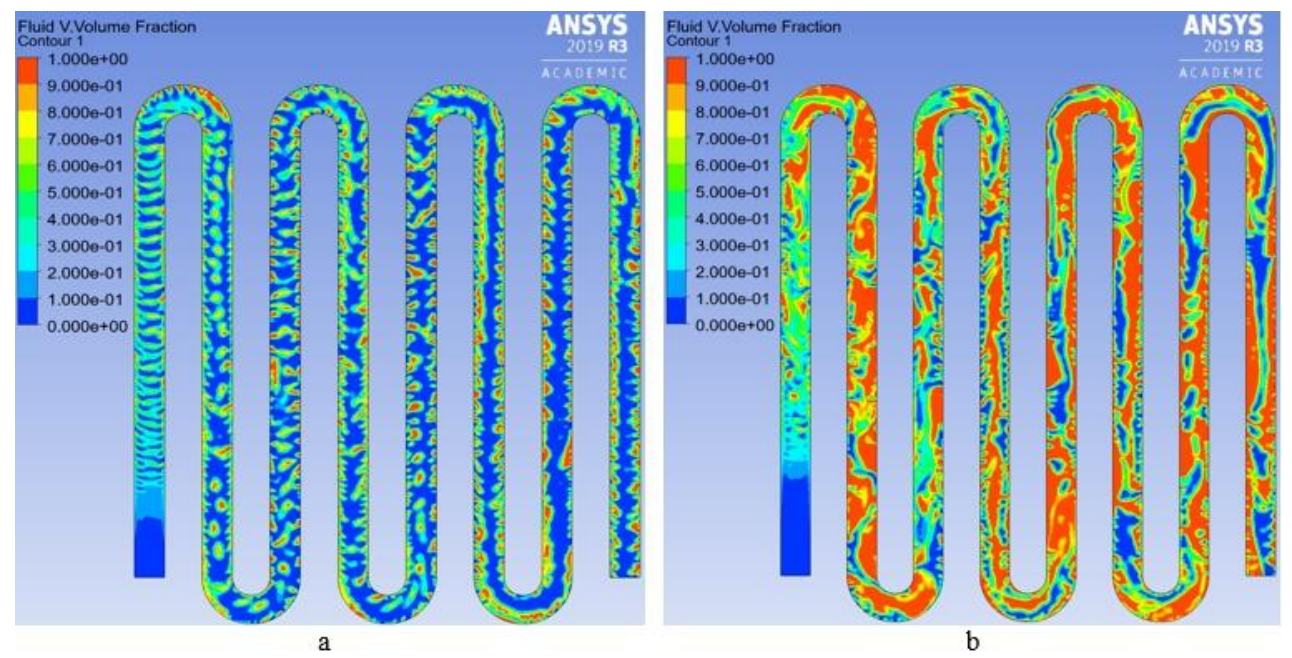

Fig.2. Steam distribution pattern ( $\mathrm{a}$ - iteration №100, b - iteration №300). 


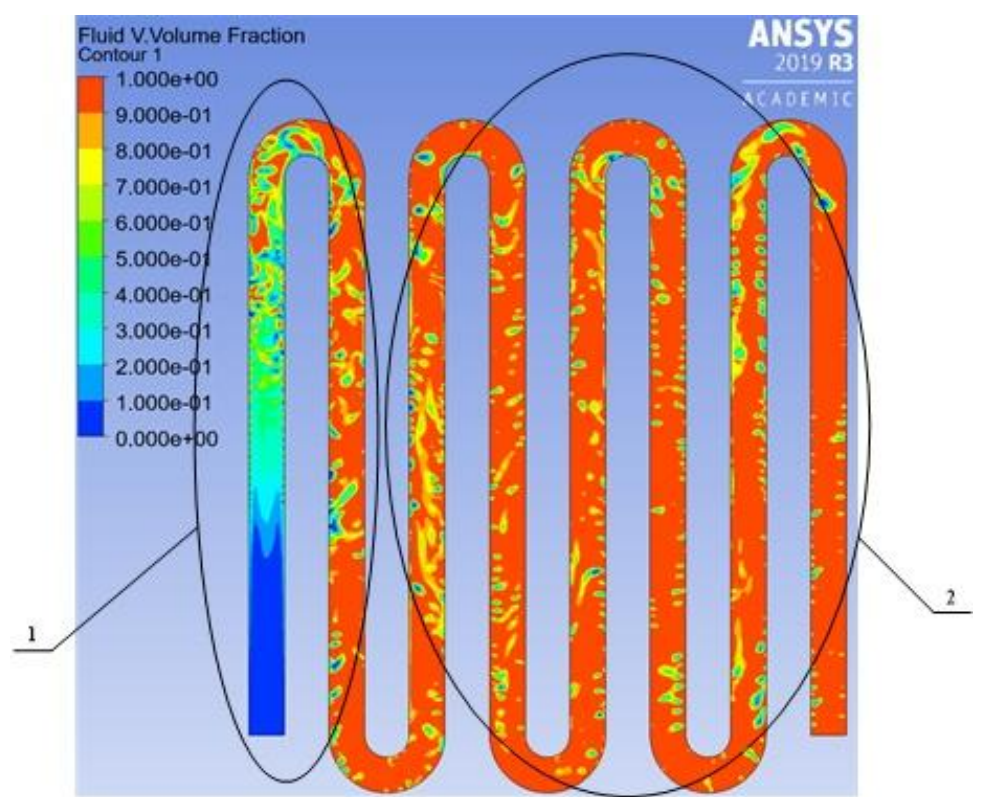

Fig.3.Resulting boiling pattern for the final iteration.

In the resulting boiling picture, 2 areas can be singled out (see Figure 3): 1 is the area of intense vaporization; 2 is the area of the same steam void. As can be seen from the presentedboiling picture, the area of intense vaporization ends after the first turn of the pipe. The area of equal steam void occupies most of the evaporator pipe. Thus, heat transfer on most of the surface of the evaporator is not effective. This is explained by the filling of the near-wall region with steam, the thermal conductivity of which is several times less than the thermal conductivity of theliquid.

To increase the efficiency of heat transfer, it is necessary to install a separator on the border of the area of intense vaporization and the area withthesame steam void. The separator will separate the liquid from the steam-water mixture and feed it back to the area of intense vaporization. The steam separated from the separator will be fed to the superheater to overheat it.

However, this raises the problem of determining the surface of the evaporator after which it is necessary to install a separator. To increase the heat transfer efficiency, it is necessary to determine in which area a sharp drop in the heat transfer coefficient occurs. For this, a study on the change in the heat transfer coefficient along the length of the pipewas conducted. An example of a change in the heat transfer coefficient overtime in one of the sections of the evaporator is shown in Figure 4. 


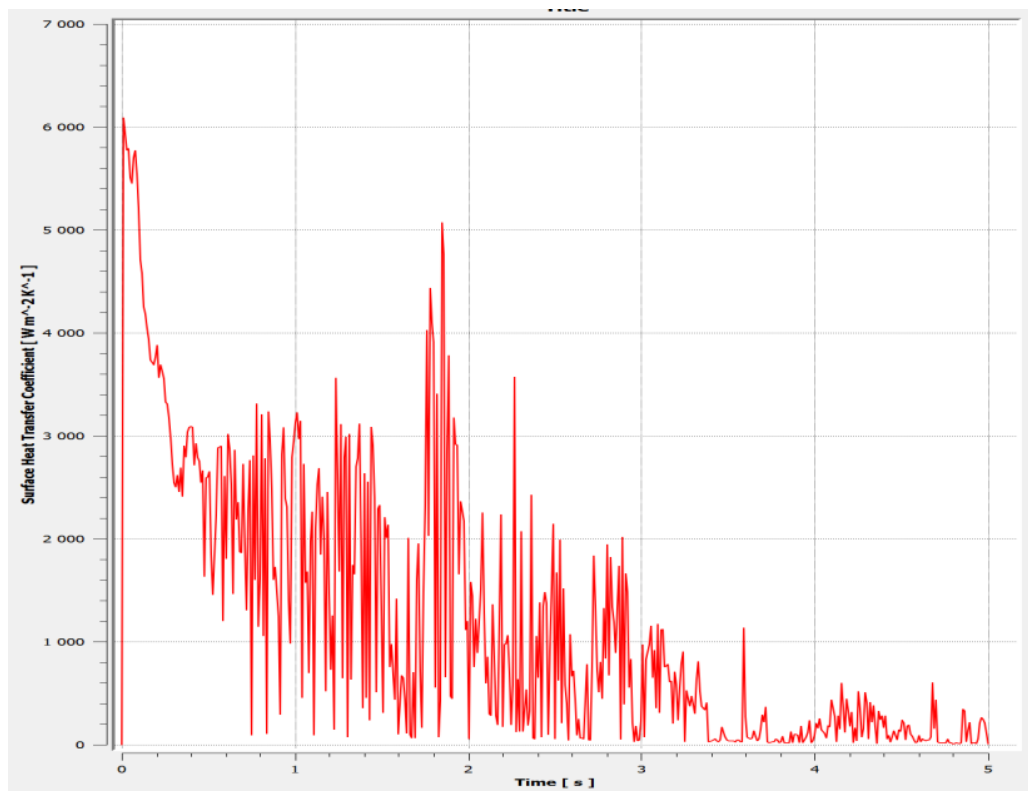

Fig. 4.Change in heat transfer coefficient over time in the evaporator section.

As a result of the study, dependence of the change in the heat transfer coefficient along the length of the evaporator pipe was obtained (Figure 5).

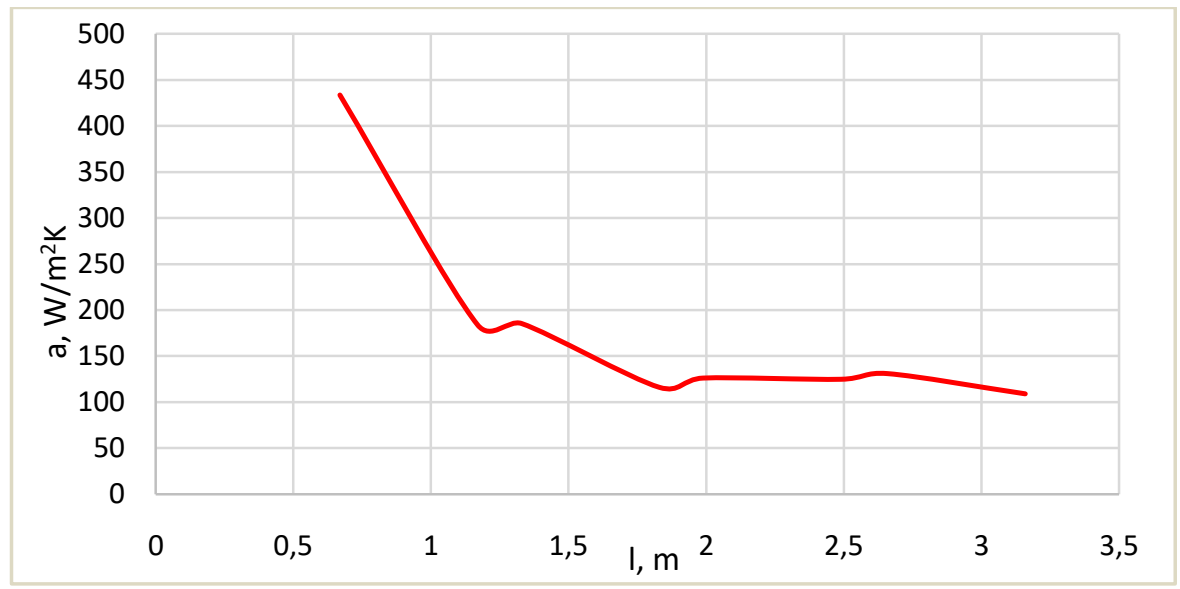

Fig. 5.Dependence of the change in the heat transfer coefficient along the length of the evaporator pipe.

The local increase in the heat transfer coefficient is explained by the degree of dryness of the steam-water mixture at these points. The lower the degree of dryness, the higher the heat transfer coefficient. When processing the measurement results, it is almost impossible to reach points with the same degree of dryness [9]. Therefore, the figure shows local increases in the heat transfer coefficient. However, as follows from Figure 5, these increases are insignificant and do not change the overall pattern of change in the heat transfer coefficient along the length of the fluid. 
As can be seen from Figure 5, a sharp drop in the heat transfer coefficient occurs in the area of $0.5-1 \mathrm{~m}$. In the following sections of the evaporator pipe, the value of the heat transfer coefficient doesn't change significantly.

Further research was carried out for a straight pipe section $0.9 \mathrm{~m}$ long with various pipe diameters, flow velocity, heat source temperatures, and fluids. The remaining parameters of the model were taken the same as for the u-shaped section. This study aims to obtain a criteria equation for calculating the Nusselt number during the boiling process, which takes into account a change in the heat transfer coefficient along the length of the pipe.

After each experiment, the values of the heat transfer coefficient were determined along the length of the pipe in a section of $0.5-0.9 \mathrm{~m}$. Also, for each point, the boiling pattern was determined. An example of the distribution of the vapor phase along the length of the evaporator pipe during the boiling process is presented in Figure 6.

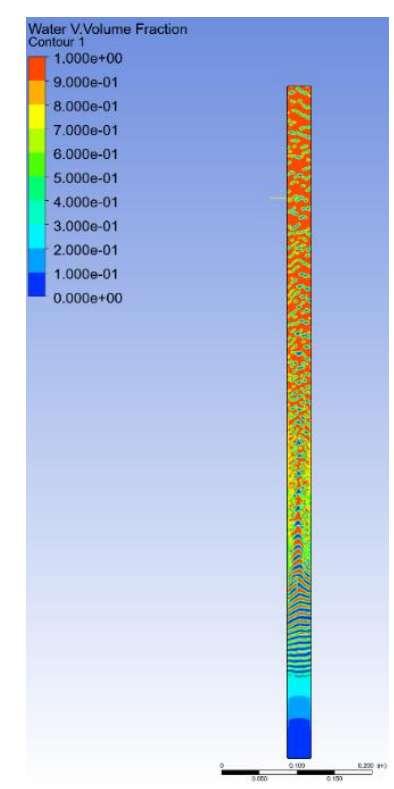

Fig. 6.Distribution of the vapor phase along the length of the evaporator pipe.

As a result of the study, the dependences of the heat transfer coefficient on the pipe diameter, fluidvelocity, pipe length, and type of fluid were obtained. The dependence of the change in the heat transfer coefficient on the pipe length for one of the experiments is shown in Figure 7. The dependence of the change in the heat transfer coefficient on the physical properties of the fluid is shown in Figure 8. The dependence of the heat transfer coefficient on the fluid velocity is shown in Figure 9. The dependence of the heat transfer coefficient on the diameter of the evaporator pipe is shown in Figure 10. 


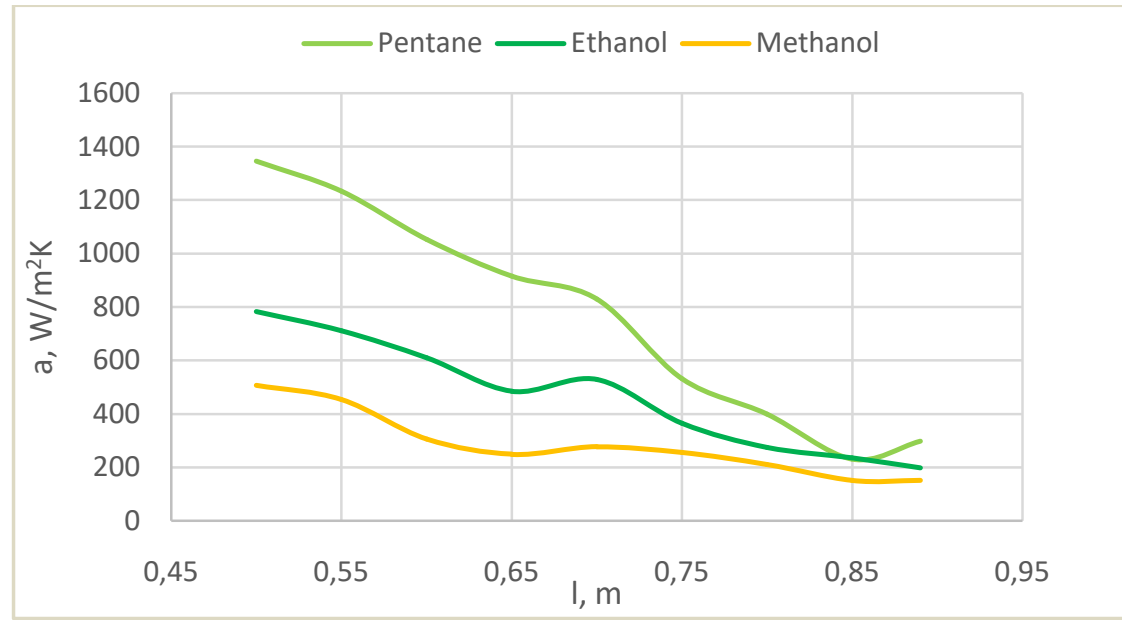

Fig. 7.Dependence of the change in the heat transfer coefficient on the pipe length.

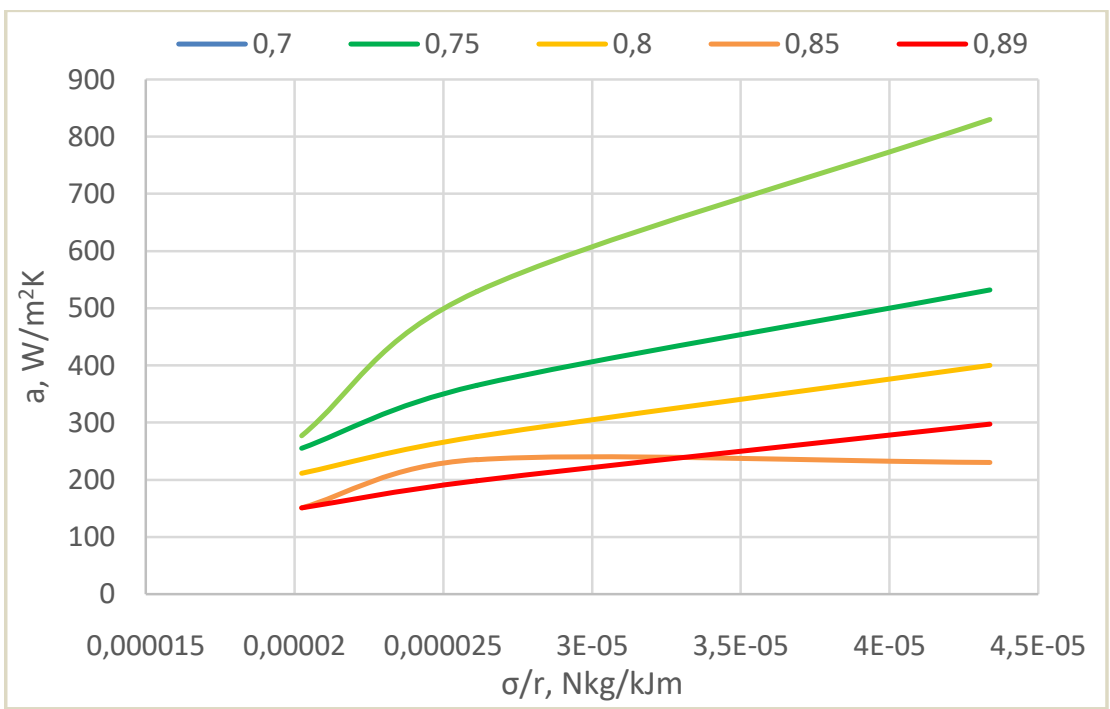

Fig. 8. Dependence of the change in the heat transfer coefficient on the physical properties of the fluid. 


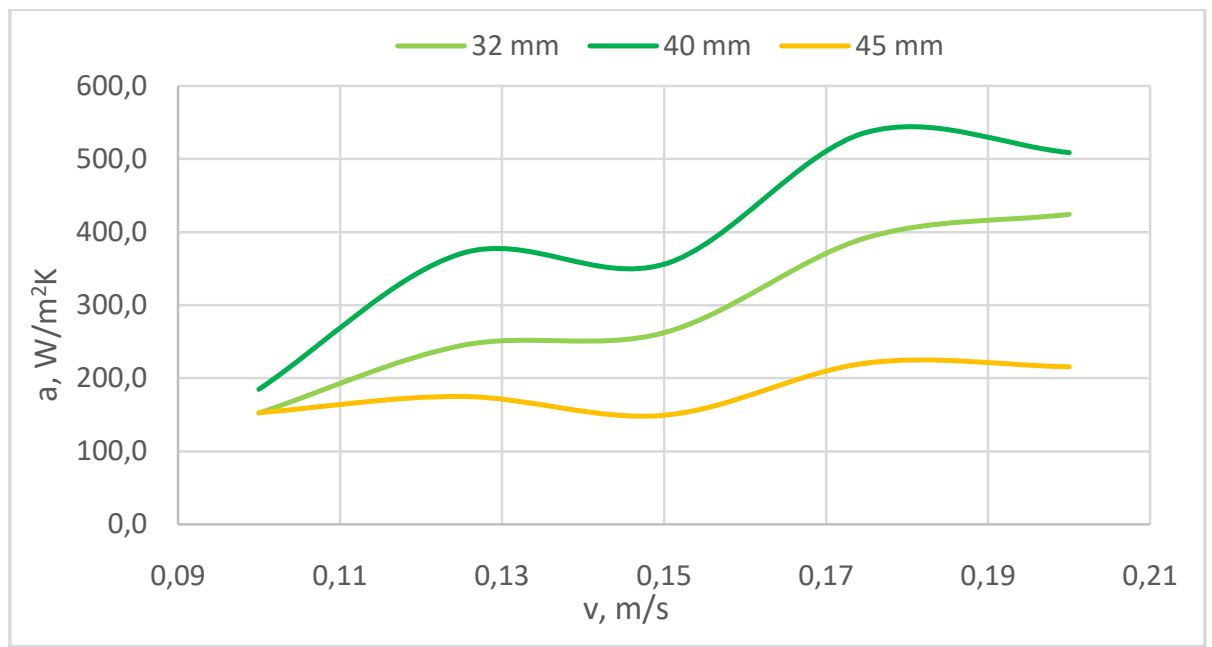

Fig.9. Dependence of the heat transfer coefficient on the fluid velocity.

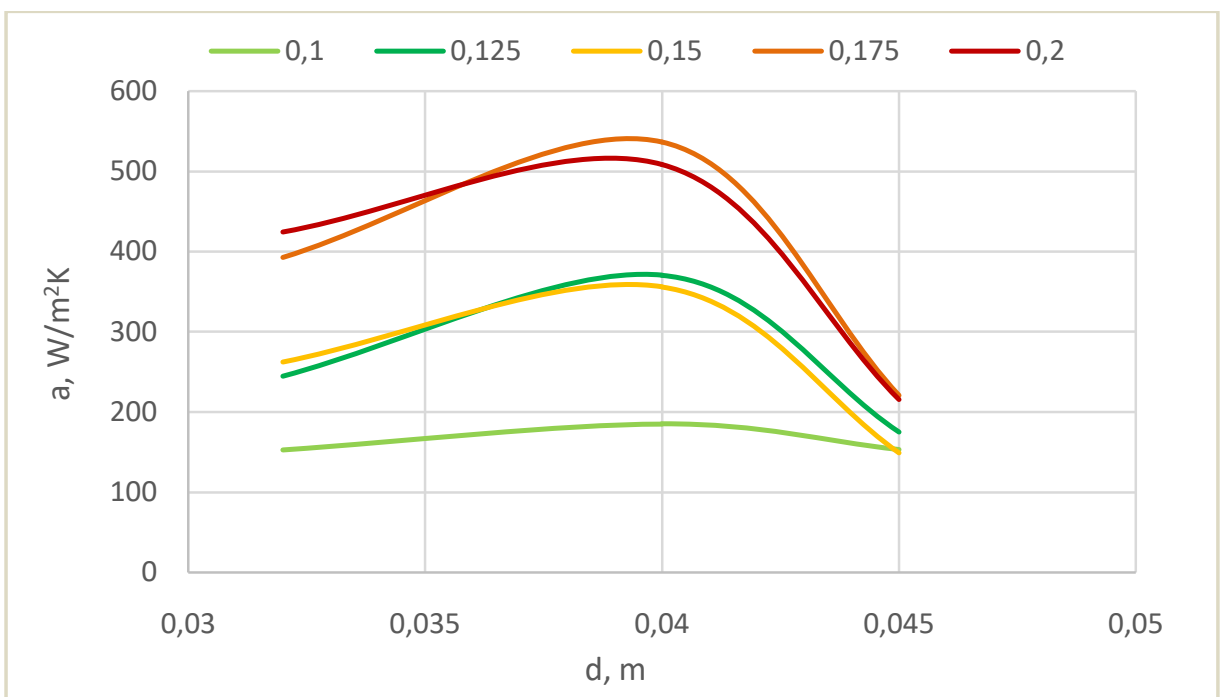

Fig. 10. Dependence of the heat transfer coefficient on the diameter of the evaporator pipe.

\section{Discussion of the results}

As can be seen from Figure 7, the heat transfer coefficient decreases with the increase of the pipe length. This is due to the fact that steam almost fills in the last sections of the evaporator tube. In this case, the heat transfer coefficient decreases due to the low thermal conductivity of vapor compared to liquid.

There is also a clear correlation betweentheincrease in the heat transfer coefficient andtheincrease in the flow velocity (Figure 9).

It can also be seen that the heat transfer coefficient increases with decreasing surface tension and decreasing heat of vaporization (Figure 8). The phenomena described above can be explained as follows. As the heat of vaporization increases, more heat must be supplied for the formation of a bubble with steam. Accordingly, the centers of vaporization and the size of the vapor bubbles become smaller than in the case of a lower heat of vaporization of the heat carrier $[10,11]$. A similar phenomenon is observed in the 
case of an increase in the surface tension of the coolant. With its increase, for the formation of a bubble with steam, more energy must be transfered, which is spent on overcoming the surface tension force [12]. Accordingly, in both cases, the intensity of the formation of vapor bubbles decreases. The degree of dryness of the steam becomes greater, which means that the heat transfer coefficient begins to fall.

The most interesting of the presentedfigures is the dependence of the heat transfer coefficient on the diameter of the evaporator pipe shown in Figure 10. As can be seen from the presented figure, with an increase in the flow velocity, the nonlinearity of the dependence on the pipe diameter increases. Thus, the heat transfer coefficient depends on the diameter not linearly, but quadratically. In other works devoted to the study of the change in the heat transfer coefficient during the boiling of an organic coolant, the dependence of the heat transfer coefficient on the pipe diameter had a linear form. In this study, a quadratic dependence on the pipe diameter was obtained, which is the novelty of this work. It was determined that there is a "critical" diameter at which the intensity of the formation of steam bubbles increases. With more intensive vaporization, a large turbulization of the flow occurs, which increases the heat transfer coefficient. With a further increase in diameter after the "critical", heat transfer coefficient begins to fall because, after this point, the formation of steam bubbles begins to be strongly influenced by the surface tension, which resists their formation onthe wall surface due to the greater amount of liquid in the pipe.

After studying all obtained dependencies and performing some transformations, an equation for calculating the heat transfer coefficient in visiblecriteriawas obtained. This equation is presented below:

$$
\alpha=1,6 \cdot 10^{6}\left((13 l-14,1) d^{2}+(-l+1,1) d+(0,019 l-0,02)\right) \cdot f(v) \cdot f\left(\frac{\sigma}{r}\right),
$$

Where:

$\alpha$ is the heat transfer coefficient, $\mathrm{W} / \mathrm{m}^{2}{ }^{\circ} \mathrm{C}$

1 is the pipe length, $m$

$\mathrm{d}$ is the pipe diameter, $\mathrm{m}$

$\mathrm{v}$ is the fluid velocity, $\mathrm{m} / \mathrm{s}$

$\sigma$ is the surface tension, $\mathrm{N} / \mathrm{m}$

$\mathrm{r}$ is the heat of vaporization, $\mathrm{kJ} / \mathrm{kg}$.

As can be seen from the equation presented above, the dependence of the heat transfer coefficient on the diameter is taken into account in the form of an equation of the second degree, which takes into account the change in the heat transfer coefficient along the length of the pipe.

The resulting equation and the proposed scheme can be used in the design of ORC installations. It can be used to determine the optimal length of the evaporator section of the steam generator, for which the optimal value of the heat transfer coefficient will be achieved.

Thus, in this work, we studied the heat transfer inside the evaporator of the ORC unit during fluidboiling. It was determined that during boiling in the evaporator tube, 2 areas stand out: the area of intensive vaporization andthearea of the same steam void. It was found that to increase the heat transfer efficiency, it is necessary to install a separator for the intermediate separation of steam from the liquid. An equation for calculating the heat transfer coefficient during boiling was obtained, taking into account the change in the heat transfer coefficient along the length of the evaporator and the nonlinear dependence of the heat transfer coefficient on the diameter. 


\section{References}

1. E.V. Burdygina Improving the energy efficiency of heat engineering equipment of primary oil refining. Abstract of dissertation for the degree of candidate of engineering. Ufa (2003).

2. E.I. Reishahrit Features of energy efficiency management at the enterprises of the oil refining industry,Journal of Mining Institute, 219, 490-497 (2016).

3. N.V. Smirnova, G.V. RudenkoTendencies, problems and prospects of innovative technologies implementation by Russian oil companies,Journal of Industrial Pollution Control,33, 937-943 (2017).

4. F.I.Abam,E.B. Ekwe, S.O.Effiom, M.C. NdukwuA comparative performance analysis and thermo-sustainability indicators of modified low-heat organic Rankine cycles (ORCs): An exergy-based procedure,Energy Reports,4, 110-118 (2018).

5. S.Safarian, F.Aramoun Energy and exergy assessments of modified Organic Rankine Cycles (ORSs),Energy Reports,1, 1-7 (2015).

6. N.N. Smirnova, E.A. IzotovMethodology for estimating heat losses due to heat effects on a heterogeneous oil reservoir,Journal of Industrial Pollution Control,33, 950-958 (2017).

7. Myeong-GieKangEffects of a flow disturbing plate on pool boiling heat transfer,International Journal of Heat and Mass Transfer,47, 757-773 (2004).

8. M.A. GrekovInvestigation of heat transfer when air flows around pipes with annular finning by methods of gradient heat measurement and thermometry. (dissertation for the degree of candidate of technical sciences. SaintPetersburg.2020).

9. M.A.Peretyatko, P.V.Yakovlev, S.A. Peretyatko, A.S.Deev, G. DyachenokThe study of heat transfer during the boiling process of organic fluid,Journal of Physics: Conference Series, 1614, (2020).

10. V.V. Fitsak, E.I. Boguslavskiy Technology and economics of near-surface geothermal resources exploitation,Journal of Mining Institute, 224, 189-198 (2017).

11. C.T.Wang, R.N. HorneBoiling flow in a horizontal fracture,Geothermics, 29, 759-722 (2000).

12. S.S. KutateladzeFundamentals of the theory of heat transfer. (Moscow: Atomizdat. 1979). 